\title{
The effect of window air inlets on office room comfort
}

\author{
Maciej Major*, Mariusz Kosiń and Izabela Major \\ Czestochowa University of Technology, Faculty of Civil Engineering, Akademicka Street 3, 42-200 \\ Częstochowa, Poland
}

\begin{abstract}
The aim of the analysis was to determine the effect of window air inlets on the distribution of thermal and humidity parameters of an office room in the heating period. The analysis included two cases: case 1 window without air inlet, case 2 - window with air inlet. Furthermore, the model includes objects that simulate two people. In order to verify the CFD analysis, tests were performed for the case 1 . The results show the difference between a window with and without air inlets.
\end{abstract}

\section{Introduction}

The subject of the study was inspired by too dry air in the analysed room, which is observed at the beginning of the heating season. One of the solutions ensuring the supply of an adequate amount of air in order to ensure thermal and humidity comfort as well as to efficiently ventilate rooms is to use window air inlets. With the ongoing changes in energy consumption demands and expectations for indoor thermal comfort, it is necessary to understand the effects of the above mentioned factors. Poor indoor air quality causes discomfort to room users. Thermal comfort in rooms has been examined by numerous researchers. Many of them have used numerical analyses, with their studies concerning three-dimensional steady-state numerical analysis in a room heated by two-panel radiators [1] or numerical evaluation of thermal comfort in a room [2] also in a cross-ventilated space with top-hung windows [3]. The numerical thermal analysis of the vertical external partitions made in the lightweight steel framing technology was analysed in [4] while author of [5] presents the results of study into the air parameters in open space offices. FEM analysis using thermal analysis is also commonly used by researches. The numerical modelling of thin-walled omega clip including heat passage by radiation and structural analysis using temperature analysis-are combined in [6], whereas simply supported carbon/epoxy composite plates in a hygrothermal environment is carried out using finite element program in [7].

In the paper, the authors used numerical simulation of heat and moisture flow. The computational fluid mechanics (CFD) provides the necessary information about the room environment [8 - 11]. Two cases were taken into account in the analysis:

- case 1: window without air inlets,

- case 2 - window with air inlets.

\footnotetext{
*Corresponding author: mmajor@bud.pcz.czest.pl
} 
The aim of the presented studies was to use CFD to determine the interaction between air inflow and thermal and humidity comfort. A simplified model of two sitting people was added to the room model. In order to verify the results obtained based on the numerical analysis, a comparison was made to the results of the performed test. The results were validated for case 1 .

The results presented in the paper can provide information on the design of rooms in terms of environmental comfort, as well as contribute to the study of comfort when using various heating and ventilation systems.

Maintaining thermal and humidity comfort at work is recommended not only to ensure adequate employee performance. Employer is obliged to adjust individual air parameters to the standards defined in [12]. Due to the fact that humans spend most of their time indoors, evaluation of these conditions is critical.

\section{Object of analysis}

The analysis concerned an office room on the last floor of the building of the Faculty of Civil Engineering, Częstochowa University of Technology in Częstochowa, Poland (Fig. 1). Room dimensions are $5.32 \mathrm{~m} \times 3.78 \mathrm{~m} \times 3 \mathrm{~m}$, with a cutout for the chimney channel with dimensions of $0.15 \mathrm{~m} \times 1.6 \mathrm{~m} \times 3 \mathrm{~m}$ (Fig. 2). There was a wall unit and three desks in the room (Figs 1a and 1b). Two cases were taken into account in the calculations. The case 1 reflected the actual condition of the room. The source of heating is a steel double panel heater with dimensions of $0.8 \times 0.6 \mathrm{~m}$. The case 2 assumed the supply of outside air through a window air inlet with dimensions of $0.4 \times 0.03 \mathrm{~m}$.

(a)

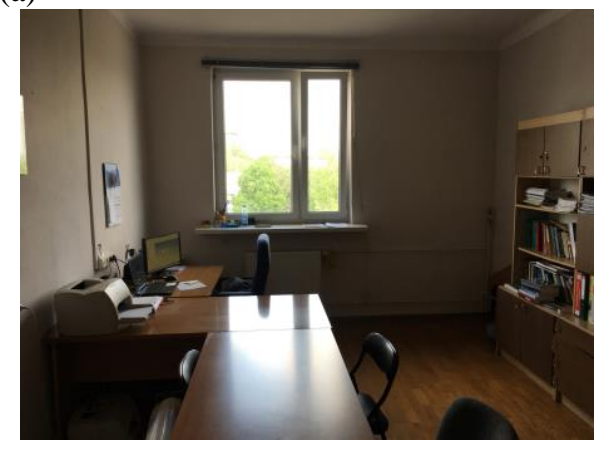

(b)

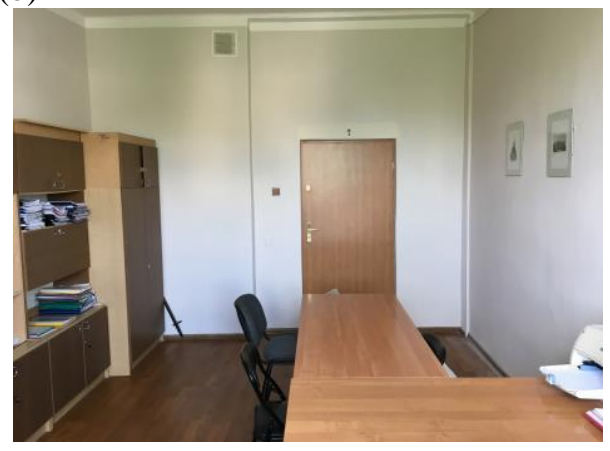

(c)

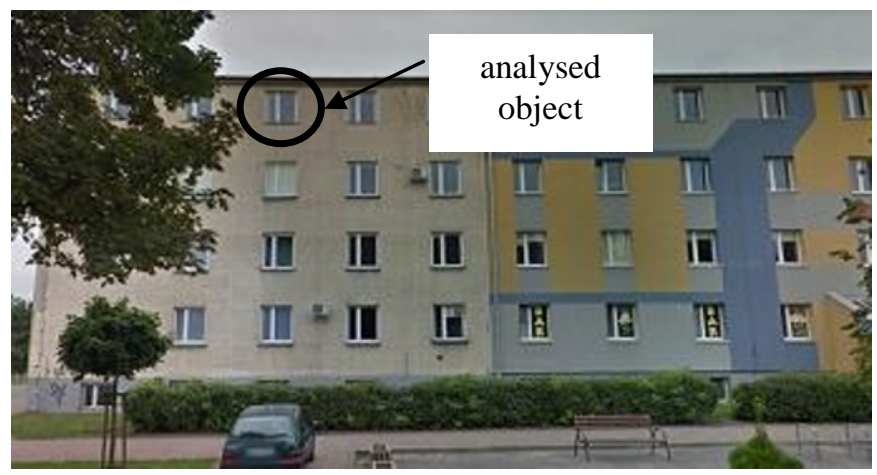

Fig. 1. View of the analysed room: a) view of the window, b) view of the door 


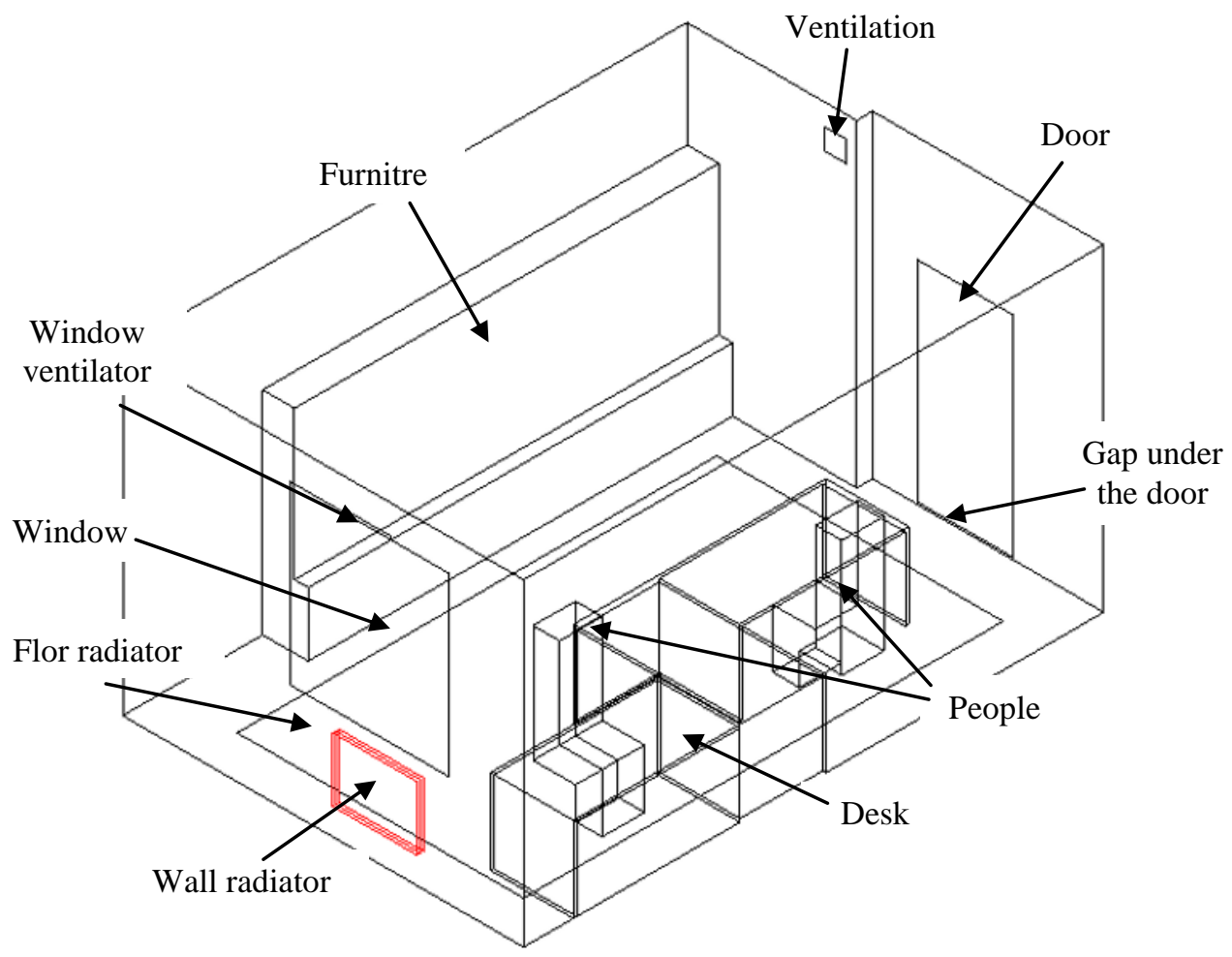

Fig. 2. Model of the room analysed

\section{Case study}

Modelling of the spatial distribution of temperature and relative humidity in accepted cases was conducted by means of the computational fluid dynamics (CFD) using Ansys Fluent 18.1 software.

Computational analysis includes the stages of geometric modelling, creation of a numerical grid, analysis and evaluation of results. The following boundary conditions were determined for the analysis: inlet - mass inlet area, outlet - mass outlet area, walls - resistant to mass flow.

A grid with four-wall components was generated in order to reduce the computation time (Fig. 3). Details of grid generation and solutions were derived from the literature [13, 14]. The computational domain was composed of nearly three million nodes.

In the analysis, the heater panel was set to $70^{\circ} \mathrm{C}$. The air velocity at the surface of the inlet opening is assumed to be $3.8 \mathrm{~m} / \mathrm{s}$, which is equivalent to wind pressure of approx. 10 $\mathrm{Pa}$. The inlet air temperature was set to a constant value of $4^{\circ} \mathrm{C}$. The mass fraction of water vapour in the inlet air was adopted based on the Mollier diagram $(4.17 \mathrm{~g} / \mathrm{kg})$. The human body was also a source of heat and moisture, for which a constant weight fraction $(10 \mathrm{~g} / \mathrm{kg})$ at body temperature of $33.4^{\circ} \mathrm{C}$ was adopted. A boundary pressure condition was used at the outlet. Air outflow was ensured by gravitational ventilation outlet with dimensions of $0.2 \times$ $0.2 \mathrm{~m}$ and a gap under the door $(0.9 \times 0.02 \mathrm{~m})$ leading to the building corridor. Temperature boundary conditions were used for the window and the external surface of the window wall. 


\section{Results}

The relative temperature and humidity for case 1 were measured to verify the computational dynamics of liquids (CFDs). The measurement place was located between people at the height of the desk, i.e. $0.8 \mathrm{~m}$ (Fig. 3a). An LB 490 recorder with a humidity sensor HIH 4000 and temperature TL2 was used for the measurements (Fig. 3b, c).

The data measured and calculated by Ansys Fluent [7] present similar trends. The differences between the results obtained from CFD analysis were estimated based on the results obtained in the study. The temperature difference is $8 \%$ for temperature and $12 \%$ for humidity. Taking into account the high number of parameters affecting the environmental climate, the results can be considered satisfactory.

(a)

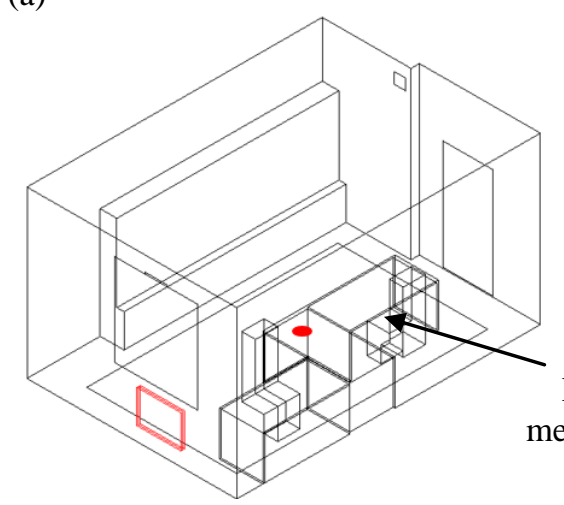

Place of

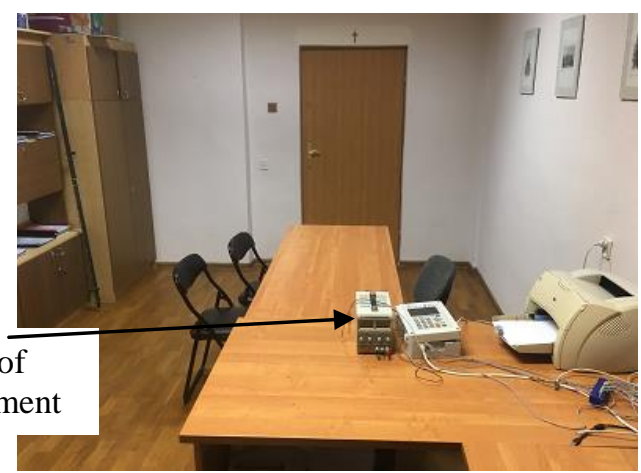

(b)

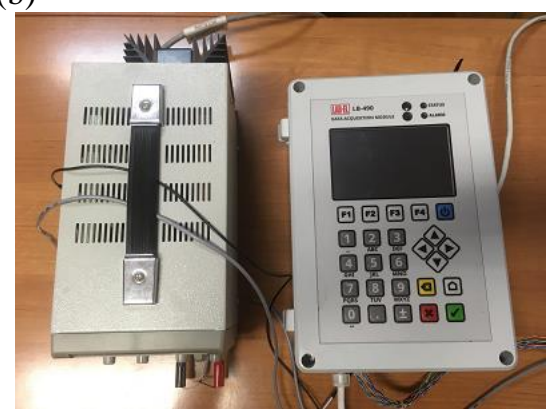

(c)

Fig. 3. Measurement of temperature and humidity: a) measuring place,

b) LB 490 recorder, c) $\mathrm{HIH} 4000$ moisture sensor and TL2 temperature sensor

Figures $4 \div 6$ in the $\mathrm{YZ}$ plane crossing one of the fields reflecting a human and in the $\mathrm{XZ}$ plane at the height of the desk show the fields of flow rate, temperature and humidity.

The air flow above the head area increases in both cases due to the higher temperature of the body surface relative to the surrounding area (Fig. 4). Around the human model, the highest air velocity is ca. $0.18 \mathrm{~m} / \mathrm{s}$ for the case 2 and ca. 20 times higher than case 1 . The speed distributions over the heater surface were similar in both cases. The maximum speed of ca. $0.55 \mathrm{~m} / \mathrm{s}$ occurred at the ceiling above the heater. A stronger air stream is observed for the window with air inlet in the ceiling area (Fig. 4b). 
(a)

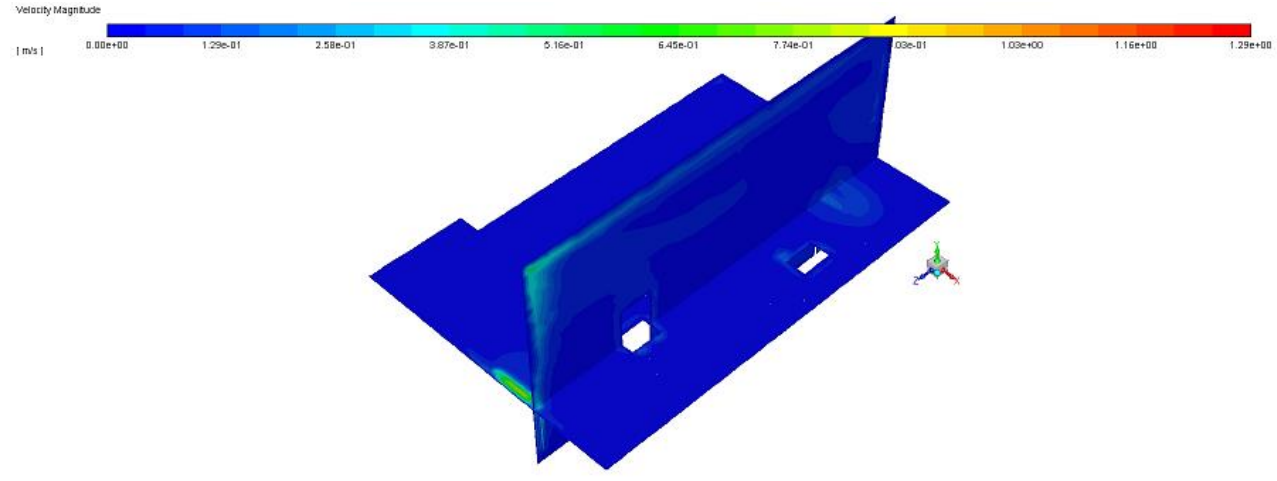

(b)

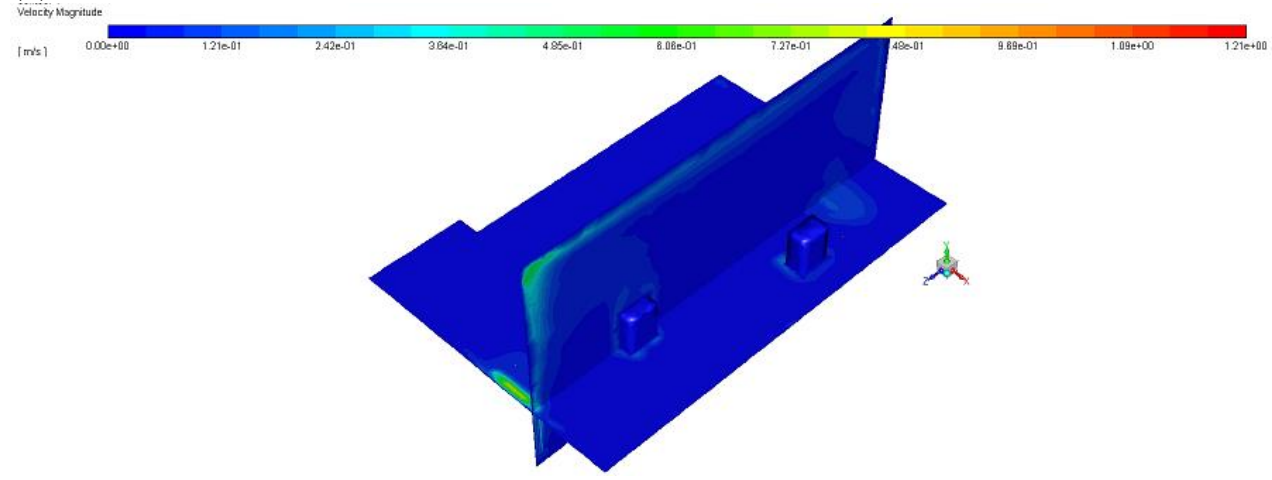

Fig. 4. Distribution of air flow in selected planes: a) case 1, b) case 2

The temperature in the head area of the human model for the window with air inlet was about $1.5^{\circ} \mathrm{C}$ lower than in the first case. A smaller effect of window temperature on the rest of the room is observed for the window part for the case 1 (Fig. 5b). In the upper office region, the temperature values were higher than in the lower area for both cases (Fig. 5).

In both cases, the climate in the room was characterized by low humidity (Fig. 6). During the heating period, the employees of the analysed office feel the dry air. This led to the above analysis concerning the improvement of this condition. Analysis of the use of window air inlets revealed that the human model area led to the increase in RH by about $5 \%$ compared to the room without air inlets.

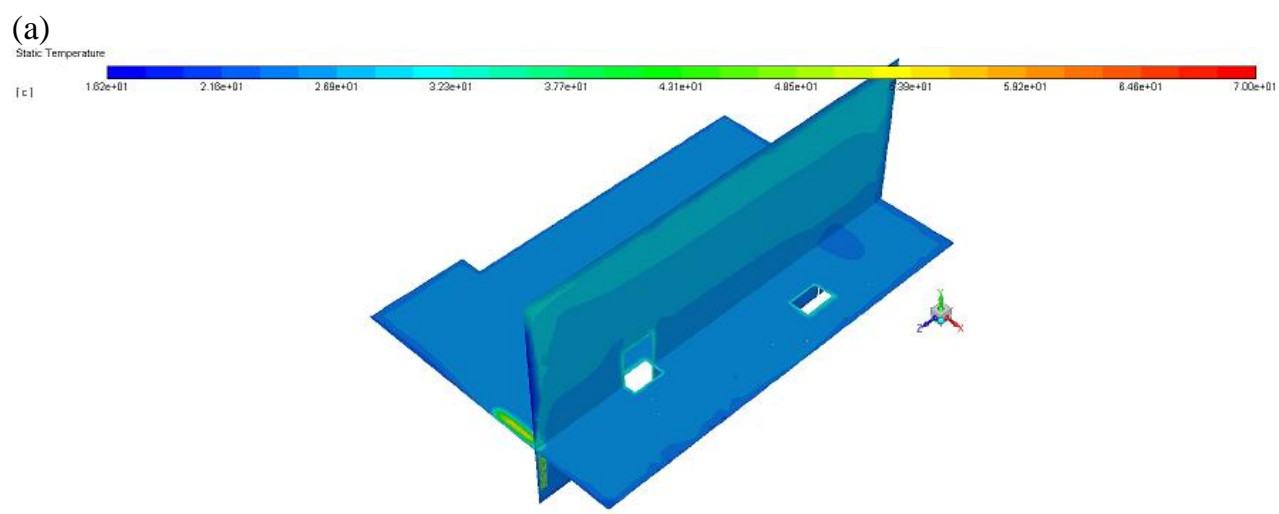


(b)

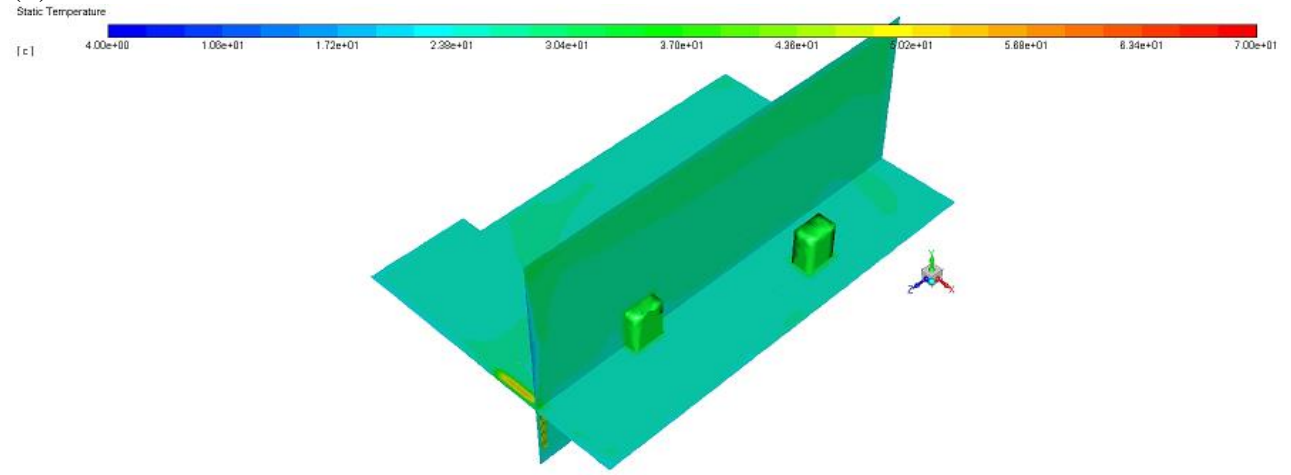

Fig. 5. Temperature distribution in selected planes: a) case 1, b) case 2

(a)

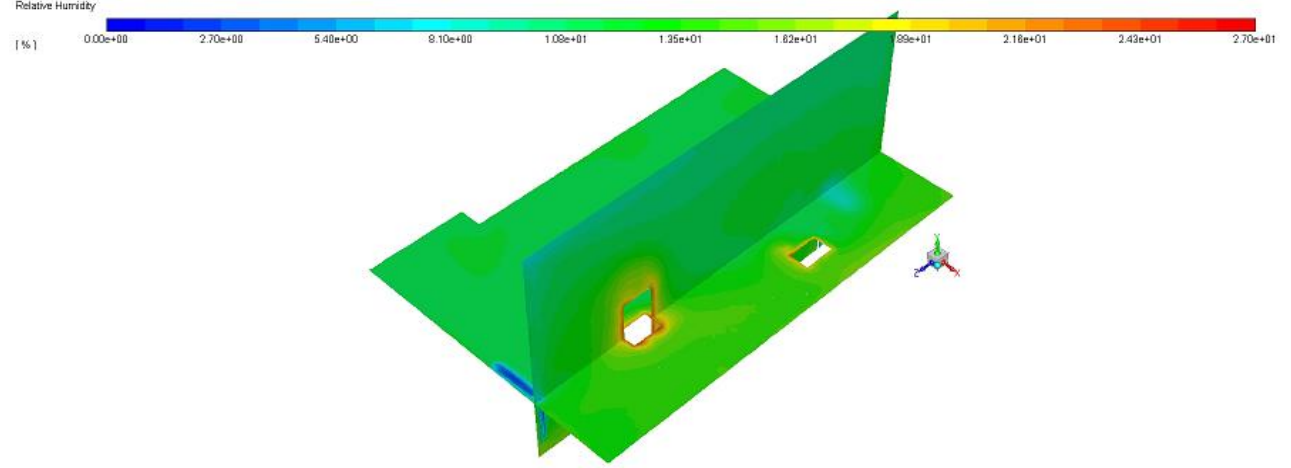

(b)

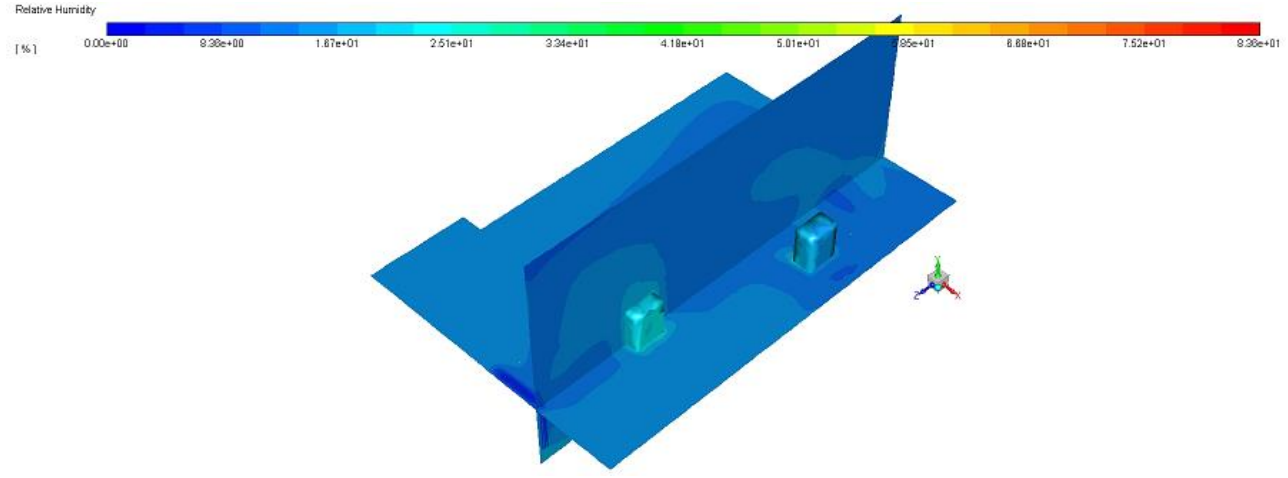

Fig. 6. Relative humidity: a) case 1 , b) case 2

\section{Summary}

The aim of the analysis was to show the effect of window air inlets on temperature and humidity distributions. The study of this case was inspired by the employees' feeling of "dry air" in the beginning of the heating season.

The results of CFD temperature and humidity in case 1 were compared with the tests. The differences between the tests and CFD were $9 \%$ for temperature and $12 \%$ for humidity. 
Taking into account the high number of parameters affecting the environmental climate, the comparative results can be considered satisfactory.

The analysis leads to the conclusion that the installation of window air inlets will increase the relative humidity of the room by a few percent. This is not an optimal condition, but it allows, with additional ventilation and temperature regulation, for the improvement in thermal and humidity conditions.

It should be emphasized that too strong a window air flow can cause discomfort to people. The distribution of speeds shown in Fig. 4 does not indicate that such an inconvenience occurred in the analysed case. Discomfort in such situations can be compensated for by choosing the right type of air inlet.

\section{References}

1. G. Sevilgen, M. Kilic, Energy and Buildings, 43, 1, 137-146 (2011)

2. M. Embaye, R.K. AL-Dadah, S. Mahmoud, Energy and Buildings, 121, 298-308 (2016)

3. X. Deng, P. Cooper, Z. Ma, G. Kokogiannakis, Energy Procedia, 121, 222-229 (2017)

4. M. Major, M. Kosiń, MATEC Web of Conferences DYN-WIND'2017, 107, 1-8 (2017)

5. D. Suszanowicz, MATEC Web of Conferences, 174, 1-9 (2018)

6. J. Flodr, M. Krejsa, P. Lehner, International Journal of Steel Structures, 11, 42, 1-7, (2019)

7. E. Kormaníková, K. Kotrasová, MATEC Web of Conferences, 76, 1-6 (2016)

8. M.W. Abdulrahman, Heat and Mass Transfer, 3rd International Conference on Fluid Flow, Heat and Mass Transfer, p 8 (2016)

9. E. Yohana, B. Yunianto, R.P. Hunadika, S. Bahar, A.A. Muhammad, Advanced Science Letters, 23, 3, 2243-2245 (2017)

10. S. Marrakchi, Z. Leemrani, H. Asselman, A. Aoukili, A. Asselman, Procedia Manufacturing, 22, 773-779 (2018)

11. X. Shan, W. Xu, Y.K. Lee, W.Z. Lu, Sustainable Cities and Society, 45, 395-405 (2019)

12. Rozporządzenie Ministra Pracy i Polityki Socjalnej w sprawie ogólnych przepisów bezpieczeństwa i higieny pracy, Dz.U. $1997 \mathrm{nr} 129$ poz. 844 z późn. zm. (in polish)

13. Ansys Fluent 12 User's Guide, Fluent Inc., Lebanon, NH, USA, (2001)

14. M. Major, M. Kosiń, Budownictwo o Zoptymalizowanym Potencjale Energetycznym, 2, 18, 55-60 (2016) 